\title{
Musculoskeletal computational analysis on muscle mechanical characteristics of drivers' lumbar vertebras and legs in different sitting postures
}

\author{
(iD) Fei Gao $0^{1,2}$ \\ (iD) Shi Zong ${ }^{3}$ \\ iD Zhi-Wu Han \\ (iD) Yang Xiao' \\ Zhen-Hai Gao'
}

1. State Key Laboratory of Automotive Simulation and Control, Jilin University, Changchun, 130025 , China 2. Key Laboratory of Bionic Engineering (Ministry of Education), Jilin University, Changchun, 130022, Jilin, P. R. China 3. China-Japan Union Hospital of Jilin University, Changchun, 130033, China

http://dx.doi.org/10.1590/1806-9282.66.5.637

\section{SUMMARY}

Using computer-aided engineering (CAE) in the concept design stage of automobiles has become a hotspot in human factor engineering research. Based on human musculoskeletal biomechanical computational software, a seated human-body musculoskeletal model was built to describe the natural sitting posture of a driver. The interaction between the driver and car in various combinations of seat-pan/ back-rest inclination angles was analyzed using an inverse-dynamics approach. In order to find out the "most comfortable" driving posture of the seat-pan/back-rest, the effect of seat-pan/back-rest inclination angles on the muscle activity degree, and the intradiscal L4-L5 compression force were investigated. The results showed that a much larger back-rest inclination angle, approximately $15^{\circ}$, and a slight backward seat-pan, about $7^{\circ}$, may relieve muscle fatigue and provide more comfort while driving. Subsequently, according to the findings above, a preliminary driving-comfort function was constructed.

KEYWORDS: Automobile driving. Automobiles. Biomechanical Phenomena. Lumbar vertebrae. Leg. Models, biological. Models, theoretical. Musculoskeletal system

\section{INTRODUCTION}

Today, prolonged sitting has been the most common work posture in the industrialized areas, especially for professions that need to use vehicles as a work tool, such as for taxi drivers. A highly comfortable car-seat not only increases the safety by relieving drivers' physical and mental fatigue but potentially enhances the psychological acceptance of consumers. Therefore, it is essential to investigate seat comfort in automotive seat development.
A reliable analysis method for measuring seat comfort must be established by combining objectively measurable comfort-quantifying parameters with subjective comfort. Traditional evaluation methods considered the content of survey items, the precise number of rating scales, a reasonable crowd positioning, and the motivation of the respondent ${ }^{1-3}$. However, it is difficult to accurately obtain information about the level of artificial muscle activity and joint strength by 
measuring the pressure distribution using traditional development means ${ }^{4,5}$.

In this study, we used a musculoskeletal humanbody model from the analysis software named AnyBody to predict muscle-activity and spinal joint force and analyzed the interaction between a passenger and a vehicle in various combinations of seat-pan and back-rest inclination angles using an inverse dynamic approach. A preliminary driving-comfort function (DCF) was created by analyzing the simulation results.

\section{METHODS}

\section{AnyBody Model}

The Anybody Modeling System, initially developed at Aalborg University, was used as a musculoskeletal model and simulation program in the present work ${ }^{6}$.

\section{Car-seat models}

A universal seat model is used in this study, which consists of five rigid bodies (head-rest, back-rest, seatpan, leg-rest, and foot-rest) and several revolute joints to adjust the inclination angle of the back-rest and seat-pan.

\section{Musculoskeletal human-body model}

The musculoskeletal human-body model used is named "seated human model", downloaded from the public-domain AnyScript Model Repository. The model contains more than 500 individual rigid bones, joints, muscles, and tendons with characteristics of physiology.

Integration of the human body and seat models

In the present work, a finite element model of a seated human was established to analyze driving fatigue. It contained a simplified human-body musculoskeletal model and a generic car-seat model. Furthermore, the bones and soft-tissue muscles were used to develop the seat-human finite element model, and the shell components of the car-seat model comprised the foot-rest, seat-base, seat-pan back-face, back-rest back-face, and head-rest back-face, and three solid components in contact with the human body, including seat-pan, back-rest, and head-rest. According to the GB10000-88 for the average Chinese adult body size, we adjusted the original human model $(167.8 \mathrm{~cm}$, $59 \mathrm{~kg}$ ) by adopting the 50th percentile of Chinese adult male body sizes, which could reflect the basic characteristics of a Chinese male.

\section{RESULTS}

Successful construction of a finite element model of a seated human

Fig.1a shows that the vertebral spine is divided into four sections. An apparent S-type for the entire upright spine is revealed, which is called the normal physiological curvature of the spine. As can be seen in Fig.1b, there are also many muscle groups in the leg that are involved in driving, including the gluteus maximus, semitendinosus, iliopsoas, sartorius, and anterior tibial. Ultimately, a seated human body model in a normal position was developed as shown in Fig.1c. According to the recommended sizes for the interior overall arrangement in passenger cars, the initial height of the seat could be set to $0.38 \mathrm{~m}$. The figures $\alpha$, $\beta$ represent the inclination angle of the back-rest and the seat-pan, respectively. The dimensions of other shell components were entered using the minimum size of design specifications, which are displayed in Fig.1c.

The effect of seat-pan/back-rest adjustment on the muscles of lumbar vertebra and legs

Next, we investigated the muscle activity degree and the distribution of the compression force in the major working muscle groups of the spine and leg using an inverse-dynamics approach in the present work.

In the musculoskeletal human-body model simulation test, the inclination angle of the back-rest and seat-pan was changed from $0^{\circ}$ to $15^{\circ}$ and adjusted $1.5^{\circ}$ at a time. As the seat inclination angle changed, there were four major working muscles in the spine affected, namely the erector spinae, semispinalis, musculus obliquus externus abdominis, and musculus transversus abdominis, which are shown in Fig.2(a)-Fig.2(d). The effect of the inclination angle change for the backrest and seat-pan on the erector spinae muscle activity degree is shown in Fig.2a. Careful observation can be found in Fig.2a, the muscle activity degree monotonically increases with the decrease of the inclination angle of the back-rest, and a reverse trend occurred for the adjustment of the seat-pan. Additionally, a larger rangeability is revealed by adjusting the inclination angle of the back-rest. Similar variation tendencies can be observed in Fig.2(b)-Fig.2(d), which describe the effect of the inclination angle change of the seat-pan 

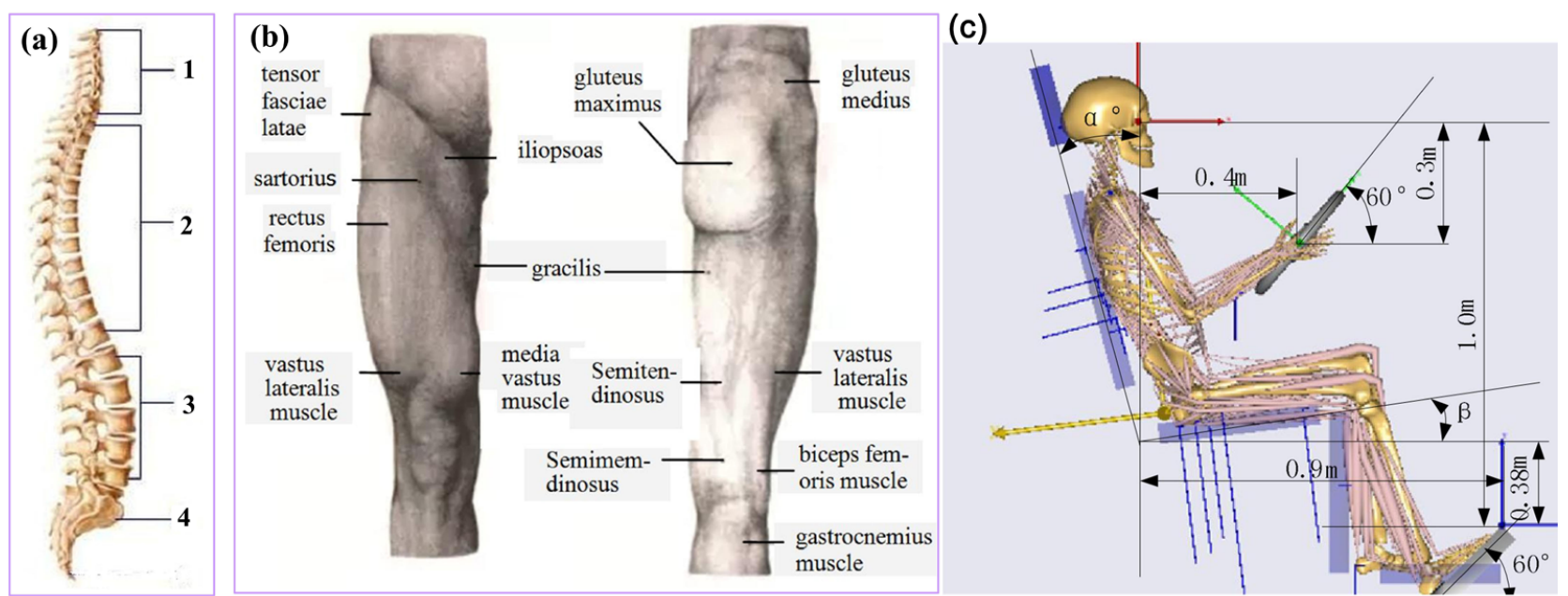

FIGURE 1. Fig.1 (a) Spinal anatomical structure in a natural upright position (1, cervical vertebra; 2 , thoracic vertebra; 3 , lumbar vertebra; 4, sacral vertebra) and (b) human muscle tissues of the legs. (c)The sitting posture for a typical driver's model.

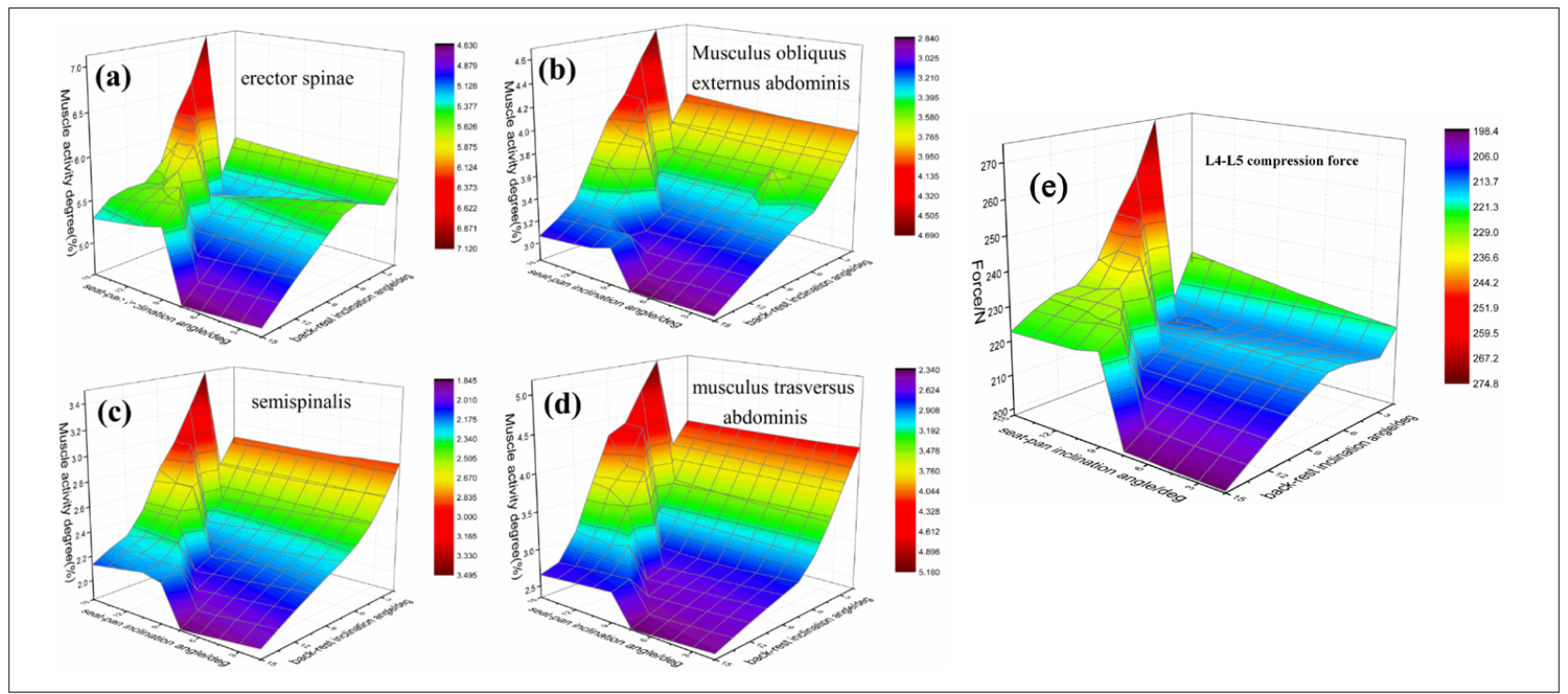

FIGURE 2. Fig.2 (a-d) The effect of inclination angle changes of the seat-pan and back-rest on the muscle activity degree of different tissues in the lumbar vertebra. (e) The effect of inclination angle changes of the seat-pan and back-rest on L4-L5 compression force.

and back-pan on the muscle activity degree of the musculus obliquus externus abdominis, semispinalis, and musculus transversus abdominis, respectively. Comparing the results in Fig.2(b)-Fig.2(d), it can be seen that the muscle activity degree of the erector spinae is the largest, about $7.12 \%$, in the red area, when the inclination angle is in the original state.

The effect of changing the inclination angle of the seat-back and seat-pan on the magnitude of the compression force in the L4-L5 of lumbar vertebra, which are investigated because of the most frequent contact with the seat, is shown in Fig.2(e). Carefully observing the result of the simulation in Fig.2(e), it can be found that the compression force suffered by the musculus transversus abdominis gradually changes as the inclination angle of the seat-rest and seat-pan is adjusted. These results obtained and shown in Fig.2 demonstrate that the reasonable adjustment of the inclination angle for the seat-rest and seat-pan helped the human-body muscles to relax.

Fig 3 shows the effect of the seat inclination angle on the activity degree of muscles of the left and right legs, including the gluteus maximus, semitendinosus, iliopsoas, sartorius, and anterior tibial. Similar results can be seen in Fig.3.

Fig.3a shows that when the inclination angle of the seat-pan is about $6^{\circ}$, the muscle activity degree of the gluteus maximus in the left leg is almost reduced to zero, while the lowest muscle activity degree in the right leg found was about $10.5^{\circ}$. Similar results for 

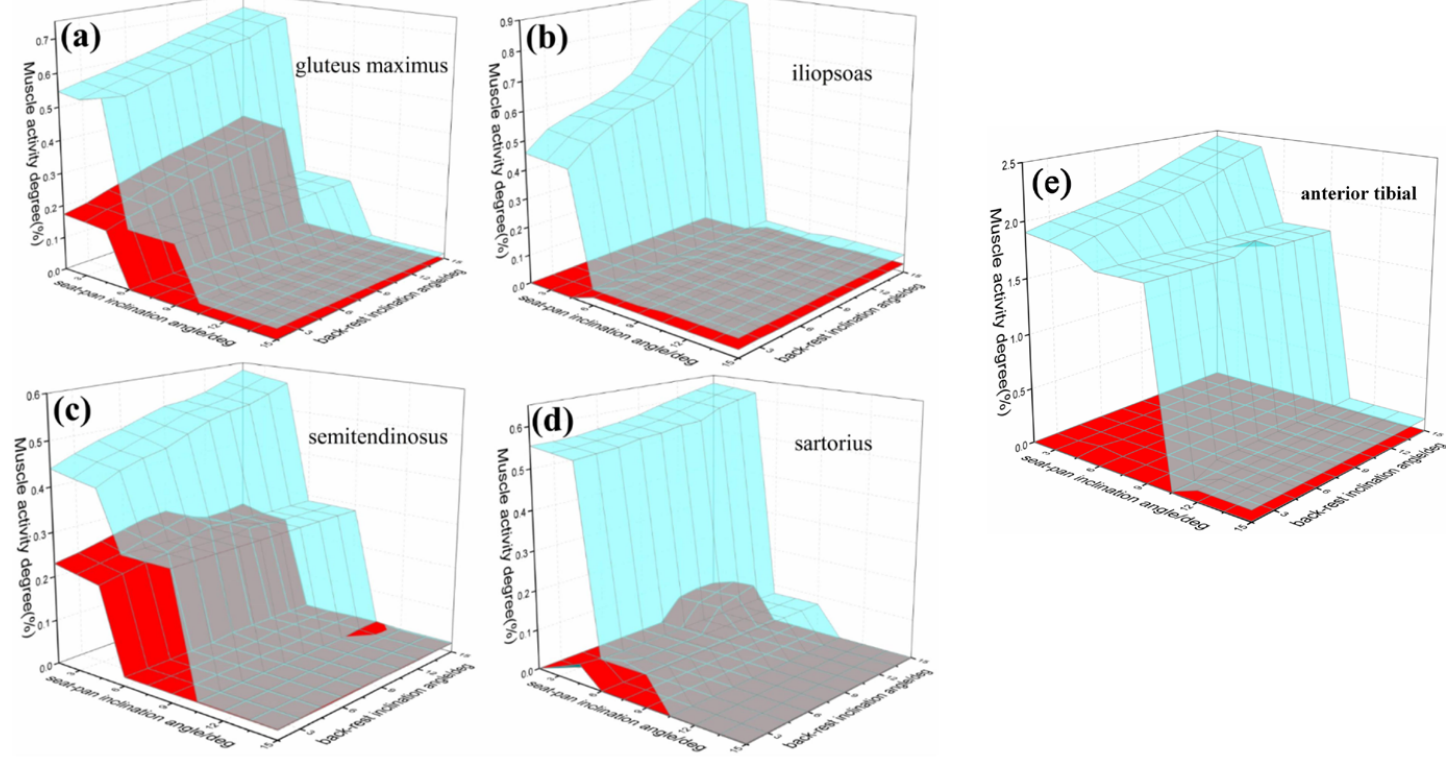

FIGURE 3. Fig.3 (a-d) The effect of variations in the seat-pan and back-rest inclination angle on muscle activity degree of the muscle tissues in legs (blue and red represent the muscle tissue in the right leg and left leg, respectively). (e) The effect of variations in the seat-pan and back-rest inclination angle on the anterior tibial muscle activity degree (blue and red represent the muscle tissue in the right leg and left leg, respectively).

the muscle tissues of the left leg can be observed in Fig.3(d)-(e), which is similar to the results shown in Fig.3a. Combined with the above analysis, from Fig.3 it can be concluded that the muscle activity degree monotonically decreases with the increase of the seatpan and back-rest inclination angle.

\section{Corresponding partial correlation coefficients}

Furthermore, several pairs of muscles, like the musculus obliquus externus abdominis, semispinalis, gluteus maximus, and semitendinosus showed a high correlation coefficient $(\mathrm{R}>0.8)$ after analyzing the correlation data. For the sake of simplifying the analysis, the muscle activity of the erector spinae (MAES), musculus transversus abdominis (MAMTA), gluteus maximus (MAGM), and anterior tibial muscle (MAATM) should be considered in the investigation of the fatigue degree for drivers with a typical driving position. Furthermore, the compression force on the L4-L5 (CFL4-L5) is important in the investigation of the degree of fatigue of drivers. As a result, the driving-comfort function (DCF) can be written as the following general formula:

DCF=MAES+MAMTA+MAGM+MAATM+CFL4-L5 (1)

\section{DISCUSSION}

The demand for car-seat comfort is constantly increasing. It is worth mentioning that, from the perspective of human biomechanics, the human-body movement is a mechanical response that is accomplished by a complex mechanical interaction between muscles, ligaments, joints, and bones, which are controlled by numerous nervous systems ${ }^{7,8}$. The static or dynamic stabilities of the human body under gravitational and other loads and precise limb behaviors depend on the tensile forces formed by working muscles in the musculoskeletal systems ${ }^{9}$. According to previous literature, the thoracic vertebra section mainly bears the seat-back support, and the most stressed points are always on the $\mathrm{T} 9, \mathrm{~T} 10$, and $\mathrm{T} 12^{10,11}$. At the same time, the compression force in the lumbar vertebra from L1 to L5 changes with different distributions of body weight, and the largest value of stress force is distributed between $\mathrm{L} 4$ and $L 5^{12,13}$. The response of the human tendon tissues could be influenced by exterior activities, like stretching or extruding, which results in increased muscle activity and a long-term feeling of muscle soreness. When the muscle activity degree is greater than 1, it exceeds the limits of muscle fatigue activity and represents a state of exhaustion. In this state of fatigue, sustained muscle stretching results in damage to the muscle tissues.

The particularity of the driver's sitting posture when driving a car was taken into account during the process of developing the finite element model, i.e, the drivers' right feet in a seating position was maintained on the footrest and the hands were placed 
on the steering wheel. For drivers who spend a lot of time driving, seating comfort control is affected by the distribution of the contact pressure on the contact interface of the seated human/car-seat.

By analyzing the relationship between the muscle activity degree and the inclination angle, we found that the activation intensity of the muscles in the lumbar vertebra is at its lowest when the inclination angle of the back-rest is $15^{\circ}$, and the inclination angle of the seat-pan only needs to be adjusted at $7.5^{\circ}$, that way the degree of muscle use can be at the minimum. However, for the muscles in legs, there is no significant influence on the muscle activity degree by adjusting the inclination angle of the back-rest, whereas a large rangeability is revealed by adjusting the inclination angle of the seat-pan.

The results in the present work demonstrated that the different muscle tissues are subject to varying degrees of compression force or activation, and the adjustment of the seat-pan/back-rest changes the pressure distribution on the muscle tissues, thus helping to relieve driving fatigue. Similar experimental methods and results have been reported in many literatures ${ }^{14,15}$. Moreover, it has been reported that lower maximum contact pressure and more uniform pressure distribution on the contact interface of the human-body/ car-seat contribute to improved seating comfort ${ }^{16}$.

The DCF was established as a new auxiliary reference method to provide a way for fabricating seats that more compliant with human comfort in the future. According to the DCF equation, the comfort of a car seat is related to the muscle activity of the working muscle groups and the compression force on the L4-L5. Hence, the driving comfort can be improved by carefully using the postural angles and seat adjustment levels.

\section{CONCLUSIONS}

This study clarified the effect of the seat-pan and back-rest inclination angle on the muscle activity degree and spinal joint force, which may improve design for car-driver comfort during driving.

\section{Acknowledgments}

This work was supported by the Nation Science Foundation of China (No.51775236), the National Key Research and Development Program of China (No. 2017YFB0102600).

\section{Competing interests}

The authors declare they have no competing interests.

\section{Author Contributions}

Conceptualization, Zhen-Hai Gao; formal analysis, Shi Zong; writing (original draft preparation), Fei Gao; writing (review and editing), Zhi-Wu Han; supervision, Yang Xiao; funding acquisition, Zhen-Hai Gao"

\section{RESUMO}

O uso de engenharia assistida por computador (CAE) na fase de projeto do conceito do automóvel tornou-se um ponto de acesso na pesquisa de fatores humanos. Com base no software computacional biomecânico musculoesquelético humano, foi construído um modelo musculoesquelético sentado para descrever a postura sentada natural de um condutor. A interação entre um motorista e um carro em várias combinações de ângulos de inclinação do assento-pan/encosto foi analisada usando uma abordagem dinâmica do verso. A fim de descobrir a postura de condução "mais confortável" do assento-pan/encosto, o efeito dos ângulos de inclinação do assento-pan/ dorso sobre o grau de atividade muscular e a força de compressão intradiscal L4-L5 foi investigado. Os resultados mostraram que um ângulo de inclinação para trás muito maior, aproximadamente $15^{\circ}$, e um ligeiro assento-pan para trás, cerca de $7^{\circ}$, pode aliviar a fadiga muscular e levar a dirigir em uma posição confortável. Posteriormente, de acordo com as conclusões acima expostas, foi construída uma função preliminar de conforto ao dirigir.

PALAVRAS-Chave: Condução de veículo. Automóveis. Fenômenos biomecânicos. Vértebras lombares. Perna (membro). Modelos biológicos. Modelos teóricos. Sistema musculoesquelético.

\section{REFERENCES}

1. Guilford JP. Psychometric methods. $2^{\text {nd }}$. New York: McGraw-Hill; 1954.

2. Oppenheim AN. Questionnaire design and attitude measurement. New York: Basic Books; 1966.

3. Grigg AO. A review of techniques for scaling subjective judgements. Supplementary Report 379. Washington: Department of the Environment and Department of Transport; 1978.
4. Grujicic MB, Pandurangan B, Xie X, Gramopadhye AK, Wagner D, Ozen M. Musculoskeletal computational analysis of the influence of car-seat design/adjustments on long-distance driving fatigue. Int J Indust Ergon. 2010;40(3):345-55

5. Majid NABA, Notomi M, Rasmussen J. Musculoskeletal computational analysis of the influence of car-seat design/adjustment on fatigue-induced 
driving. In: Modeling, Simulation and Applied Optimization (ICMSAO), $20114^{\text {th }}$ International Conference on (pp. 1-6). IEEE Press. https://doi. org/10.1109/ICMSAO.2011.5775600.

6. Damsgaard M, Rasmussen J, Christensen ST, Surma E, Zee M. Analysis of musculoskeletal systems in the anybody modeling system. Simul Model Pract Theory. 2006;14(8):1100-11.

7. El'ner AM. Postural adjustments to voluntary movements. Electrical activity of muscles and biomechanics of the human body in an upright position. Biofizika. 1993;38(1):187-91.

8. Lu TW, Chang CF. Biomechanics of human movement and its clinical applications. Kaohsiung J Med Sci. 2012;28(2 Suppl):S13-25.

9. Watkins J. Structure and function of the musculoskeletal system. $2^{\text {nd }}$ ed. Champaign: Human Kinetics; 2010.

10. Iyer S, Christiansen BA, Roberts BJ, Valentine MJ, Manoharan RK, Bouxsein $\mathrm{ML}$. A biomechanical model for estimating loads on thoracic and lumbar vertebrae. Clin Biomech (Bristol, Avon). 2010;25(9):853-8.
11. Borkowski SL, Sangiorgio SN, Bowen RE, Scaduto AA, He B, Bauer KL, et al. Strength of thoracic spine under simulated direct vertebral rotation: a biomechanical study. Spine Deform. 2016;4(2):85-93.

12. Corlett EM, Eklund JA. How does a backrest work? App Ergon. 1984;15(2): 111-4.

13. Mehta CR, Tewari VK. Biomechanical model to predict loads on lumbar vertebra of a tractor operator. Int J Indust Ergon. 2015;47:104-16.

14. Ferrari R. Sitting biomechanics. Part II: optimal car driver's seat and optimal driver's spinal model. J Manipulative Physiol Ther. 2001;24(2):140-3.

15. Park SJ, Kim CB, Kim C), Lee JW. Comfortable driving postures for Koreans. Int | Indust Ergon. 2000;26(4):489-97.

16. Grujicic M, Pandurangan B, Arakere G, Bell WC, He T, Xie X. Seat-cushion and soft-tissue material modeling and a finite element investigation of the seating comfort for passenger-vehicle occupants. Materials \& Design. 2009;30(10):4273-85 